\title{
Focus prosody in Brahvi and Balochi
}

\author{
Nasir A. Syed ${ }^{1}$, Abdul Waheed Shah ${ }^{1}, Y i X u^{2}$ \\ ${ }^{1}$ LUAWMS, Uthal, Pakistan \\ ${ }^{2}$ Department of Speech, Hearing and Phonetic Science, University College London, UK \\ nasirabbassla@gmail.com, waheedshah47@gmail.com, yi.xu@ucl.ac.uk
}

\begin{abstract}
Previous research has shown that post-focus compression (PFC) - the reduction of $\mathrm{F}_{0}$ and intensity after a focused word, is present in some languages but absent in many others. It has been hypothesized that the cross-linguistic distribution of PFC parallels that of the Nostratic macro-family. The present study is a test of this Nostratic-origin hypothesis through a comparison of focus prosody in Brahvi, a Dravidian language, and Balochi, an Indo-Iranian language, both alleged members of the Nostratic macro-family. Twenty native speakers from each language produced declarative sentences with different focus conditions. Acoustic analysis showed that, in both languages, post-focus $\mathrm{F}_{0}$ peaks are significantly lower than those in baseline neutral-focus sentences. But post-focus lowering of $\mathrm{F}_{0}$ and intensity is greater in Balochi than in Brahvi. These results offer evidence that at least one of the Dravidian languages has PFC, which is consistent with the Nostraticorigin hypothesis. The weaker form of PFC in Brahvi, however, suggests that factors that may weaken PFC in a language need to be investigated, and other Dravidian languages also need to be studied for the presence of PFC.
\end{abstract}

Index Terms: post-focus compression, PFC, Nostratic macrofamily, Dravidian languages, Brahvi, Balochi

\section{Introduction}

Since the seminal work of Cooper, Eady and Mueller [1], it is known that the realization of prosodic focus in languages like English involves not only phonetic enhancement of focused words themselves, but also reduction of post-focus words in pitch range and intensity [2]. Such post-focus compression (PFC) is shown to be highly effective in cueing perceptual identification of focus $[2,3,4]$. Despite the perceptual efficacy, however, it is also found that PFC is not universal, because many languages do not show significant pitch range and intensity compression after focus [5]. Furthermore, the crosslinguistic distribution of PFC seems to have a geographic pattern. In China, for example, PFC occurs consistently in the northern dialects $[6,7,8]$, while southern dialects and languages often lack PFC $[2,6,9]$. A further finding is that PFC is easily lost but impossible to gain through language contact [11], which rules out the possibility that it is a feature that emerges freely in various languages. These observations have led to the hypothesis that languages with PFC have all inherited it from their ancestral languages, which are linked ultimately to a common protolanguage $[2,9]$. The fact that PFC is found in Indo-European languages, Altaic languages, Uralic Languages, Indo-Iranian languages, and some Afro-Asiatic languages [9] further suggests that there is a similarity between its distribution and that of the Nostratic Macro-family [12]. The Nostratic is a hypothesized macro-family proposed by Pederson [12] that consists of the above-mentioned language families as well as the Dravidian and Kartvelian families. An interesting parallel to the Nostratic hypothesis is the Farming/Language Dispersal Hypothesis [14], which posits that the distribution of languages of the world today have mostly resulted from the spread of farming from major agriculture origins. Among the origins, the oldest is the Fertile Crescent which is the birthplace of the wheat- and barley-based farming [15]. It is likely, therefore, that $\mathrm{PFC}$ is a feature originating from the proto-Nostratic language, which then spread through the expansion of wheatand barley-based farming across much of the Euro-Asia continent.

The Nostratic origin hypothesis is falsifiable by testing its predictions. A clear case of falsification would be that a language with no plausible link to the Nostratic macro-family is found to have PFC, as it would mean that independent emergence of PFC is possible, thus rejecting the core inheritance assumption of the hypothesis. Another type of falsification would be that a Nostratic language is found to have no PFC, and there are no plausible explanations for its absence.

The present study is a test of the Nostratic origin hypothesis by investigating focus prosody in two languages spoken in the Balochistan province of Pakistan. One is Balochi, an IndoIranian language, and the other is Brahvi, a Dravidian language. Balochi is expected to have PFC, based on a positive finding on Persian [15]. The case of Brahvi is less certain. It should have PFC if the Dravidian family belongs to the Nostratic macrofamily [12]. But there have been disagreements on the classification of Dravidian languages [16, 17], and there is also genetic evidence showing differences between the Dravidian and Aryan populations in the Indo subcontinent [14].

\section{Method}

\subsection{Stimuli}

Three short declarative sentences in each language were constructed, each comprising of three disyllabic words with only sonorant consonants. Paired with each target sentence were $4 w h$-questions that would prompt the sentence to be read with neutral, initial, medial and final focus. One of the tree target sentences and their corresponding wh-questions for both languages are shown in Table 1.

Table 1: Sample target sentences and prompt questions.

\section{Balochi}

\begin{tabular}{ll}
\hline Target & Noori Nama Wani. [Noori reads the name] \\
\hline Q1 & Noori Che Kan? [What does Noori do?] \\
\hline Q2 & Kae Nama Wani? [Who reads the name] \\
\hline
\end{tabular}




\begin{tabular}{ll}
\hline Q3 & Noori Che Wani? [What does Noori read?] \\
\hline Q4 & $\begin{array}{l}\text { Noori Nama Che Kan? [What does Noori do } \\
\text { with the name?] }\end{array}$ \\
\hline Brahvi & \\
\hline Target & Nana mama narra. [our uncle fled.] \\
\hline Q1 & Ant Mas? [What happened?] \\
\hline Q2 & Dina mama narra? [Whose uncle fled?] \\
\hline Q3 & Nana dair narra? [Our which relative fled?] \\
\hline Q4 & Nana mama ant kary? [What did our uncle do?] \\
\hline
\end{tabular}

\subsection{Participants and procedures}

For Balochi, twenty male native speakers were recruited, who were aged between 20 and 33 years, with an average of 25.25 (standard deviation 3.09). All participants were students at Lasbela University of Agriculture, Water and Marine Sciences (LUAWMS), Uthal, Balochistan, Pakistan. For Brahvi, twenty male native speakers from the Khuzdar district (speaking Jhalawan (southern) dialect) were recruited. Their age ranged between 18 and 31 years with an average of 23.75 (standard deviation 3.26). None of the participants reported speech or hearing disabilities. They were paid for their participation.

The recording was done at a computer laboratory in the Department of English Language and Literature, LUAWMS, Uthal (Balochistan). The question-answer pairs were presented on a web browser controlled by a Javascript program. The program presented the stimuli in three repetition blocks, each with a different randomization order. Each participant therefore produced 3 sentences $* 4$ focus conditions $* 3$ repetitions $=36$ utterances. The randomization orders were different for each participant. Before each recording session, the participant was informed in their mother tongue about the procedure, but was not told about the purpose of the experiment.

During each trial, the experimenter, a native speaker of the language, read aloud the question, and the participant answered the question by reading aloud the target sentence. For each language, an observer who knew both languages was also present to make sure everything was going on well. The audio recording was done with a Sony digital audio recorder at the sampling rate of $44,100 \mathrm{~Hz}$.

\subsection{Acoustic analysis}

The recordings were analyzed with ProsodyPro [18], a script for Praat [19], to take measurements of fundamental frequency $\left(\mathrm{F}_{0}\right)$, intensity and syllable duration. The main objective was to examine, for each of the two languages, whether there is PFC, i.e., the reduction of pitch range and intensity in post-focus words as compared to the neutral focus words in the same sentence and position.

Figures 1 and 2 display mean $\mathrm{F}_{0}$ contours of the Balochi and Brahvi sentences in four focus conditions. The contours are time-normalized and averaged across repetitions and speakers. The normalization makes it possible to make direct comparisons between the focus conditions.

Error! Reference source not found. shows that, in Balochi, $\mathrm{F}_{0}$ contours vary substantially across focus conditions. In initial focus, the focused words have much higher $F_{0}$ peaks than the same words in neutral focus, and post-focal $F_{0}$ peaks are much lower than those in the neutral focus condition. In medial focus, however, there is neither clear on-focus increase or post-focus decrease of $\mathrm{F}_{0}$ peaks.

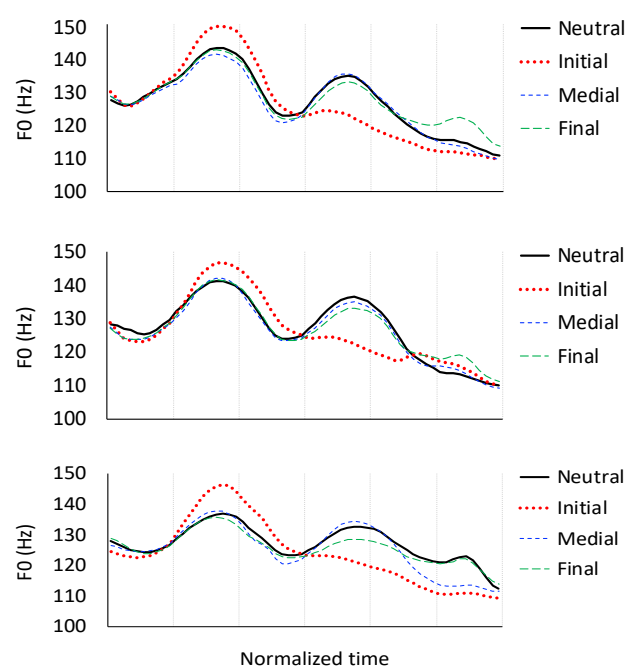

Figure 1: Time-normalized mean $F_{0}$ contours of three Balochi sentences in four focus conditions. Vertical lines mark syllable boundaries.

For Brahvi, as shown in Figure 2, on-focus $\mathrm{F}_{0}$ peaks are slightly higher than those of the same words in the neutral focus condition, especially in sentence 1 . Post-focus $F_{0}$ peaks are lower than those of the neutral focus peaks in all three sentences. But the magnitude of the difference is not as large as that in Balochi as shown in Figure 1.

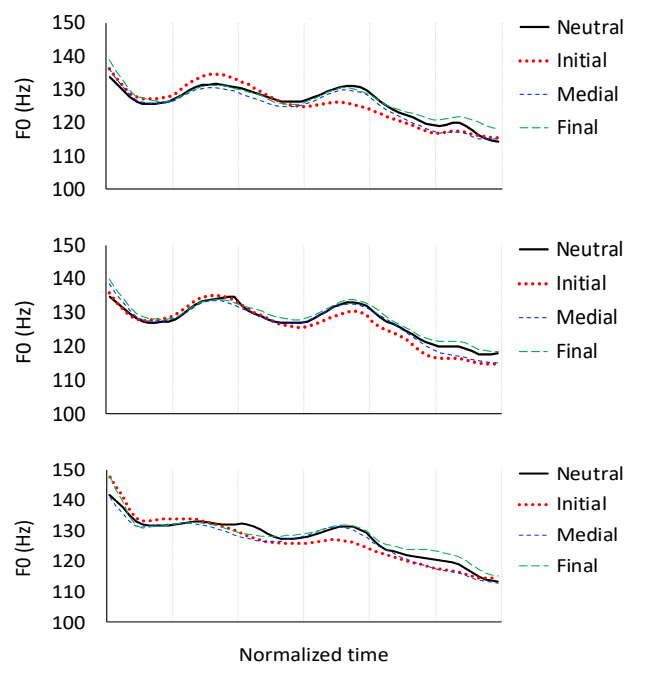

Figure 2: Time-normalized mean $F_{0}$ contours of three Brahvi sentences in four focus conditions. Vertical lines mark syllable boundaries.

\subsection{Numerical comparisons and statistical analysis}

Three types of measurements were obtained with ProsodyPro: maximum $\mathrm{F}_{0}(\operatorname{maxf0})$, syllable duration and mean intensity. These measurements were also used as dependent variables in a series of repeated measures ANOVAs. The comparisons were done separately for pre-, on- and post-focus words and for the two languages. Each time the words in a focused condition were compared to the same words in the corresponding neutral focus 
condition. The independent factors were focus (pre-, on- and post-focus) and focus location (initial, medial and final).

\subsubsection{Pre-focus words in Balochi}

For Balochi, focus had no effect on pre-focus maxf0 but it was significantly higher before medial focus than before final focus $\left(\mathrm{F}_{1,19}=9.99, p=0.005\right)$. There was no interaction between focus and focus location on maxf0. Intensity was marginally lower before medial focus than before final focus $\left(\mathrm{F}_{1,19}=5.07\right.$, $p=0.036)$ and the effect of focus location was highly significant $\left(\mathrm{F}_{1,19}=40.78, p<.0001\right)$. But there was no interaction between focus and focus location. For syllable duration, again there was no effect of focus, but it is significantly longer before final focus than before medial focus $\left(\mathrm{F}_{1,19}=9.82, p=0.01\right)$. The interaction of focus and focus location was significant $\left(\mathrm{F}_{1,19}=8.92, p=0.01\right)$.

\subsubsection{Pre-focus words in Brahvi}

For Brahvi, again focus had no effect on pre-focus maxf0, neither was there effect of focus location or interaction between the two factors. For intensity, there was no significant effect of focus, position or their interaction. For syllable duration, there is no significant effect of focus nor interaction of focus and focus location. However, syllable duration was again significantly longer before final focus than before medial focus $\left(\mathrm{F}_{1,19}=12.80, p=0.002\right)$. There is no interaction between the two factors.

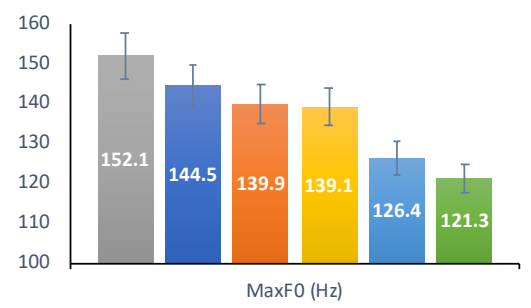

On-focus, Initial - Neutral, Initial On-focus, Medial Neutral, Medial On-focus, Final - Neutral, Final
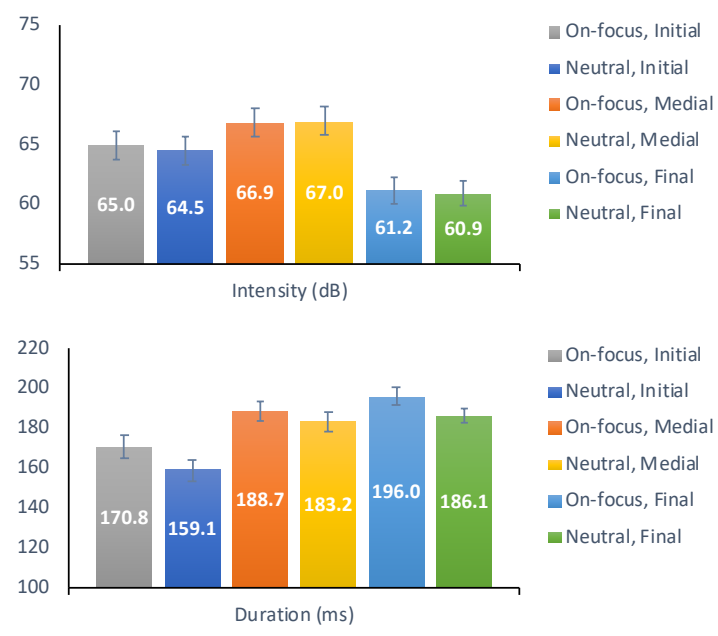

Figure 3: Maxf0, intensity and syllable duration of onfocus words in different focus conditions in Balochi, with standard errors

\subsubsection{On-focus words in Balochi}

Figures 3 shows maxf0, intensity and syllable duration in onfocus words across different focus and focus location conditions for Balochi. Maxf0 was significantly higher in on- focus words than in neutral focus words $\left(\mathrm{F}_{1,19}=10.78, p=.004\right)$, and significantly higher in earlier locations than in later locations $\left(\mathrm{F}_{1,19}=35.18, p<.0001\right)$. There was also an interaction between focus and focus location on maxfo $\left(\mathrm{F}_{1,19}=\right.$ $5.12, p=.011)$.

For intensity, there was no focus effect, but there was a significant effect of focus location $\left(\mathrm{F}_{1,19}=210.56, p<.0001\right)$. The interaction between focus and locus was marginally significant for intensity $\left(\mathrm{F}_{1,19}=4.035, p=.026\right)$.

For syllable duration, there was a significant on-focus increase $\left(\mathrm{F}_{1,19}=30.48, p>.0001\right)$, and a significant effect of focus location $\left(\mathrm{F}_{1,19}=15.39, p<.0001\right)$. But there was no interaction between the two factors.

\subsubsection{On-focus words in Brahvi}

The effects on on-focus word for Brahvi are shown in Figure 4. There was no focus effect on maxf0, but focus location had a significant effect $\left(\mathrm{F}_{2,38}=9.74, p<0.001\right)$. there was no interaction between the two factors.

For intensity, the effect of focus was also non-significant. But there is a significant effect of focus location $\left(\mathrm{F}_{1,19}=52.89\right.$, $p<0.001)$. There was no interaction between the two factors.

For syllable duration, there was no focus effect, but the effect of focus location was significant $\left(\mathrm{F}_{2,38}=61.38, p<\right.$ 0.001 ), and there was no interaction between the two factors.
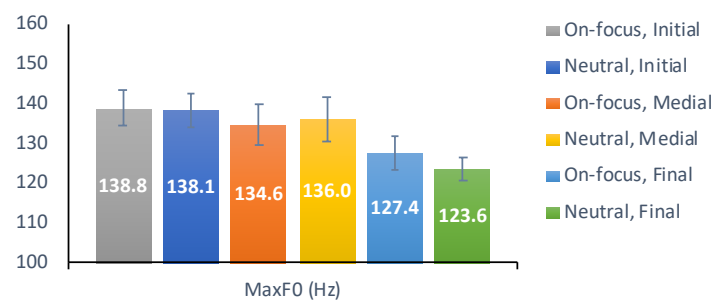

$\operatorname{MaxF0}(\mathrm{Hz})$

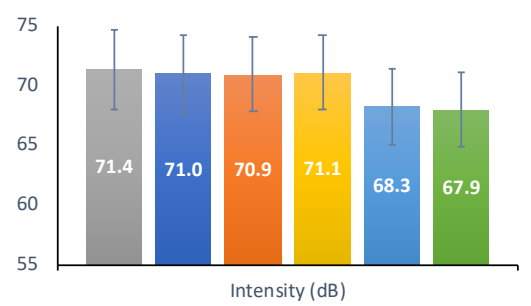

- On-focus, Initial - Neutral, Initial On-focus, Medial - Neutral, Medial - On-focus, Final - Neutral, Final

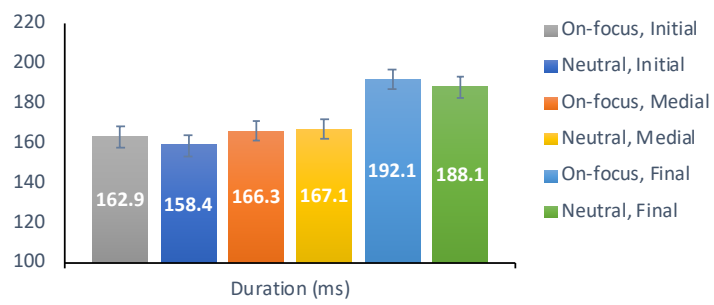

Figure 4: Maxf0, intensity and syllable duration of onfocus vs. neutral focus words in Brahvi, with standard errors

\subsubsection{Post-focus words in Balochi}

Figures 4 shows maxf0, intensity and syllable duration in postfocus words across different focus and focus location conditions for Balochi. Maxf0 was significantly lower in postfocus words than in neutral focus words $\left(\mathrm{F}_{1,19}=54.00, p\right.$ 
$<.0001)$. Also maxf0 was significantly higher when focus was sentence-initial than when it was sentence-medial $\left(\mathrm{F}_{1,19}=33.63\right.$, $p<0.0001)$. There was also a weak interaction between focus and focus location on $\operatorname{maxf0}\left(\mathrm{F}_{1,19}=7.33, p=0.014\right)$, indicating that post-focus lowering of maxf0 was stronger in initial focus than in medial focus.

Post-focus intensity was significantly lower than that in neutral-focus words $\left(\mathrm{F}_{1,19}=35.31, p<0.0001\right)$, and it was also lower after sentence-initial focus than after sentence-medial focus $\left(\mathrm{F}_{1,19}=156.441, p<0.0001\right)$. There was also an interaction between focus and focus location $\left(\mathrm{F}_{1,19}=15.132, p\right.$ $=0.001$ ).

There was a significant focus effect on syllable duration $\left(\mathrm{F}_{1,19}=64.170, p<0.0001\right)$, but the pattern was different when focus was sentence-initial from when it was sentence-medial, as can be seen in the bottom graph of Figure 5. There was, however, no focus location effect on syllable duration, but the interaction between focus and focus location was marginally significant $\left(\mathrm{F}_{1,19}=6.133, p=0.023\right)$.
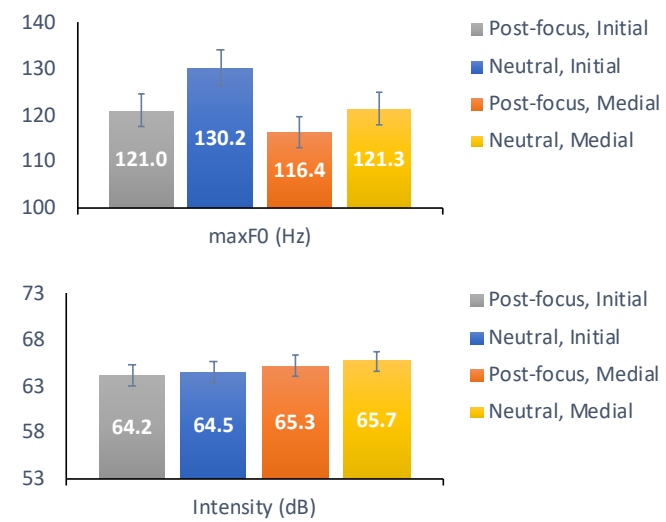

- Post-focus, Initial

- Neutral, Initial

- Post-focus, Medial

Neutral, Medial

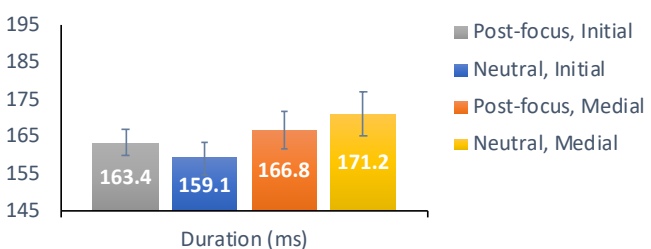

Figure 5: Maxfo, intensity and syllable duration of post-focus vs. neutral focus words in Balochi, with standard errors

\subsubsection{Post-focus words in Brahvi}

For Brahvi, as shown in Figure 6, maxf0 was significantly lower in post-focus words than neutral-focus words $(\mathrm{F}=7.18$, $p=0.015)$, it was also significantly higher after initial focus than after medial focus $\left(\mathrm{F}_{1,19}=10.09, p=0.005\right)$. But there was no interaction between the two factors.

Intensity was significantly lower in post-focus than neutralfocus words $\left(\mathrm{F}_{1,19}=12.215, p=0.002\right)$, and it was also significantly lower after medial-focus than after initial-focus $\left(\mathrm{F}_{1,19}=74.563, p<0.001\right)$. But there was no interaction between the two factors.

Syllable duration was significantly shorter in post-focus than neutral-focus words $\left(\mathrm{F}_{1,19}=12.96, p=0.002\right)$, it was also shorter after initial-focus than after neutral focus $\left(\mathrm{F}_{1,19}=\right.$ 74.437, $p<0.001$ ). But there was no interaction between the two factors.
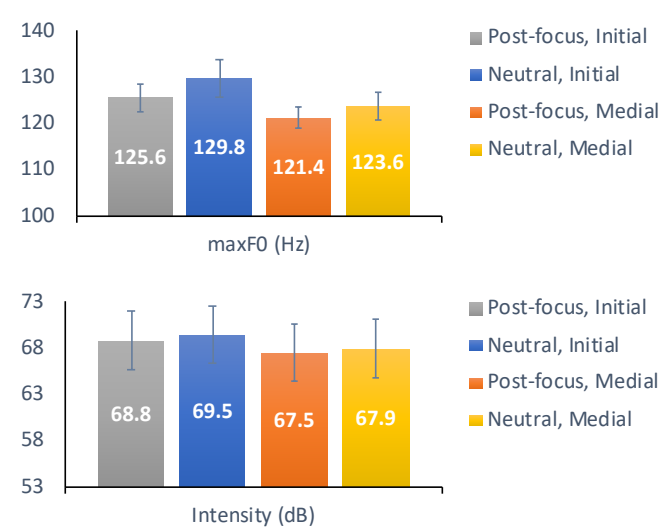

Post-focus, Initial

- Neutral, Initial

- Post-focus, Medial

- Neutral, Medial

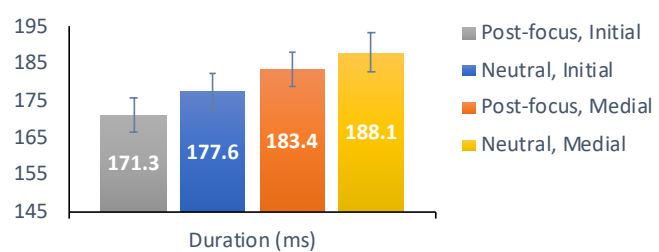

Figure 6: Maxf0, intensity and syllable duration of post-focus vs. neutral focus words in Brahvi, with standard errors.

\section{Discussion and conclusion}

Overall, the results show that the most consistent effect of focus is the lowering of $F_{0}$ and intensity of post-focus words relative to corresponding neutral-focus words, indicating that PFC occurs in both languages. On the other hand, the effect on $\mathrm{F}_{0}$ is much weaker in Brahvi than in Balochi, as can be seen in the means $F_{0}$ contours in Figures 1 and 2. Some effects of focus are also found in on-focus words, but again they are weaker in Brahvi than in Balochi. There is significant on-focus increase of $\mathrm{F}_{0}$ and duration in Balochi, but not in Brahvi, and there is no on-focus increase of intensity in either language.

There are also many significant effects of focus location on maxf0, intensity and duration, but they are likely related to well-known phenomena of declination [20], whereby $\mathrm{F}_{0}$, and sometimes intensity, tend to decrease over the course of an utterance, and boundary marking, whereby syllable duration increases continually over the course of an utterance, due to final lengthening at the right edge of words, phrases and sentences [21].

The weaker PFC effects in Brahvi than in Bolochi is an intriguing finding, as the two languages are spoken in the same geographic area, and many speakers are bilinguals of both languages. There are two possible sources of weakening of PFC. One is that there may be interaction of focus with other communicative functions as already noted in some studies [22]. The second is that PFC may have been weakened through language contact, just as it can be lost through language contact [2]. Dravidian languages are known to have a longer history in the Indo subcontinent than Indo-Iranian languages like Baloshi. It is possible that the early migrants of the Dravidian speaking population had close contacts with the indigenous languages in the area, resulting in the weakening of PFC. Further research, however, is needed to examine this possibility, including the investigation of other Dravidian languages. 


\section{References}

[1] Cooper, W. E., Eady, S. J., and Mueller, P. R., "Acoustical aspects of contrastive stress in question-answer contexts," Journal of the Acoustical Society of America vol. 77, pp. 2142-2156, 1985.

[2] Chen, S.-w., Wang, B., and Xu, Y., "Closely related languages, different ways of realizing focus," in Proceedings of Interspeech 2009, Brighton, UK, 1007-1010, 2009.

[3] Xu, Y., Xu, C. X., and Sun, X., "On the Temporal Domain of Focus," in Proceedings of International Conference on Speech Prosody 2004, Nara, Japan, 81-84, 2004.

[4] Rump, H. H., and Collier, R., "Focus conditions and the prominence of pitch-accented syllables," Language and Speech vol. 39, pp. 1-17, 1996.

[5] Xu, Y., "Post-focus compression: Cross-linguistic distribution and historical origin," in Proceedings of The 17th International Congress of Phonetic Sciences, Hong Kong, 152-155, 2011.

[6] Wang, B., Wang, L., and Qadir, T., "Prosodic encoding of focus in six languages in China," in Proceedings of The 17th International Congress of Phonetic Sciences, Hong Kong, 144147, 2011.

[7] Shen, C., and Xu, Y., "Prosodic Focus with Post-focus Compression in Lan-Yin Mandarin," in Proceedings of Speech Prosody 2016, Boston, USA, 340-344, 2016.

[8] Duan, W., and Jia, Y., "Contrastive study of focus phonetic realization between Jinan dialect and Taiyuan dialect," in Proceedings of 2015 International Conference Oriental COCOSDA held jointly with 2015 Conference on Asian Spoken Language Research and Evaluation (O-COCOSDA/CASLRE), 47-52, 2015.

[9] Wu, W. L., and Xu, Y., "Prosodic Focus in Hong Kong Cantonese without Post-focus Compression," in Proceedings of Speech Prosody 2010, Chicago, 2010.

[10] Wang, B., Zhang, Y., Xu, Y. et al., "Prosodic focus in three northern Wu dialects: Wuxi, Suzhou and Ningbo," in Proceedings of ExLing 2017, Heraklion, Greece, 117-120, 2017.

[11] Chen, Y., Xu, Y., and Guion-Anderson, S., "Prosodic realization of focus in bilingual production of Southern Min and Mandarin," Phonetica vol. 71, pp. 249-270, 2014.

[12] Bomhard, A. R., "The Current Status of Nostraitic Studies," The Macro Comparative Journal vol. 1, pp. 1-24, 2011.

[13] Diamond, J., and Bellwood, P., "Farmers and their languages: the first expansions," Science vol. 300, no. 5619, pp. 597-603, 2003.

[14] Diamond, J. M., Guns, germs and steel: a short history of everybody for the last 13,000 years: Random House, 1998.

[15] Taheri-Ardali, M., and Xu, Y., "Phonetic Realization of Prosodic Focus in Persian," in Proceedings of Speech Prosody 2012, Shanghai, 326-329, 2012.

[16] Winters, C., "Did the Dravidian Speakers Originate in Africa?," BioEssays vol. 27, no. 5, pp. 497-498, 2007.

[17] Pagani, L., L Pagani, V., Colonna, C. et al., "An ethnolinguistic and genetic perspective on the origins of the Dravidian-speaking Brahui in Pakistan," Man in India vol. 97, pp. 267-278, 2017.

[18] Xu, Y., "ProsodyPro - A tool for large-scale systematic prosody analysis," in TRASP 2013 - Tools and Resources for the Analysis of Speech Prosody, Aix-en-Provence, France, Proceedings, 7-10, 2013.

[19] Boersma, P., "Praat, a system for doing phonetics by computer," Glot International vol. 5:9/10, pp. 341-345, 2001.

[20] Ladd, D. R., "Declination: A review and some hypotheses," Phonology Yearbook vol. 1, pp. 53-74, 1984

[21] Nakatani, L. H., O'connor, K. D., and Aston, C. H., "Prosodic aspects of American English speech rhythm," Phonetica vol. 38, pp. 84-106, 1981

[22] Lee, A., and Xu, Y., "Revisiting focus prosody in Japanese," in Proceedings of Speech Prosody 2012, Shanghai, 274-277, 2012. 